\title{
nature
}

\section{Better news - perhaps - on global warming}

Evidence is emerging that carbon emissions may have started to fall, in advance of ratification of the Kyoto Protocol. If so, containing global warming may turn out to be less painful than has sometimes been supposed.

$\mathrm{R}$ ecent surveys by the Worldwatch Institute, in Washington DC, and by the Energy Information Administration (EIA) of the US Department of Energy suggest that carbon dioxide emissions fell slightly last year - despite robust economic growth - both globally and in the United States (see page 494). While the data are insufficient to provide firm evidence of a clear trend, these findings at least give both sides of the global warming debate a rare opportunity to share the same piece of good news.

The EIA, an independent statistics unit in the energy department, found that carbon emissions held steady in the United States last year, and that industrial emissions dropped by 1.2 per cent, even as the economy grew at the exceptional rate of 4 per cent. The Worldwatch Institute, meanwhile, estimates that global emissions fell by 0.5 per cent in 1998, at a time when the world economy grew by 2.5 per cent.

The institute reports that China, whose emissions are widely recognized to be critical to any global effort to tackle the greenhouse gas problem, managed to cut them by almost 4 per cent, even as its economy boomed. All of this tentatively suggests that carbon emissions can be reduced without inflicting the economic damage that critics of the Kyoto Protocol say will be the inevitable consequence of rigid adherence to its targets for reductions.

It is prudent, of course, to note the statistics' potential limitations. The decline in US emissions may well be partially attributable to a mild winter there last year, or to other extraneous factors. And it remains unclear whether China's reported drop in emissions is either accurate or sustainable.

At the same time, a number of developments that can be linked to the Kyoto process would seem likely to contribute to cuts in the growth of emissions. In particular, many large corporations have set their own targets, and have begun to implement them - even in advance of international ratification of the Kyoto agreement. Perhaps heightened awareness of global warming will, on its own, make a significant contribution to curtailing emissions growth - an important lesson in itself.

That would be just as well, since representatives of developed and developing countries are said to be making little progress towards settling their unresolved differences on the implementation of the Kyoto Protocol, and the Clinton administration clearly lacks the votes in the Senate to win its ratification in the United States.

More evidence that the connection between economic growth and emissions growth has been severed may be the best hope left for those who want more intensive action to forestall global warming. Such evidence would isolate hard-line opposition to emissions restrictions, cool the heated rhetoric of the global warming debate, and open the way for a relatively painless transition to a world of lower carbon emissions.

\section{Yes, minister, but ...}

Britain's BSE inquiry is providing a valuable lesson in the relationship between science and public policy.

W /hen the full history of Britain's handling of its crisis over bovine spongiform encephalopathy — BSE, or 'mad cow disease' - comes to be written, the transcript of the current inquiry being held under Justice Phillips will be a key text. And few passages of that transcript are likely to be as rich, particularly as an illustration of the highly complex relationship between science and politics, as last week's evidence by former and current members of the Spongiform Encephalopathy Advisory Committee (see page 490).

The committee was set up in 1990 on the recommendation of an earlier inquiry headed by Sir Richard Southwood, formerly professor of zoology at the University of Oxford. Its remit was a sensible and desirable one - or, at least, it appeared that way at the time: namely, to keep an eye on what was known and what was not known scientifically about the nature of BSE, how it was spreading among British beef herds, and its possible implications. In particular, these included the likelihood, previously described by the Southwood committee as "remote", that BSE could spread from cattle to humans.

In practice, this remit appears to have been impossible to meet. Politicians and government officials, under intense pressure to provide statements that could be used as public justification of a particular course of action (or, just as frequently, inaction), perhaps inevitably sought to draw on the conclusions of a group of scientific experts who could be held to be independent. Most notable was when John Gummer, the minister of agriculture at the time, invoked the name of David Tyrrell, then chair of the committee, when he stated that "What Tyrrell says, I will do".

It will be up to Phillips, whose inquiry is due to finish at the end of the year, to determine whether a crucial mark was overstepped in compromising the responsibility of a committee whose original brief was restricted to science alone. The present evidence indicates that this did indeed happen, although the full response from the civil servants and others involved is yet to be known. What is already clear, however, is that the inquiry has revealed the need for a much sharper definition of the role of science advisers in policy making.

The publication and propagation of guidelines on just this topic by Sir Robert May, the government's chief scientist, is an important step in the right direction. Even these, however, appear to argue for maintaining a sharp distinction between the scientific and the political. One of the key questions that the Phillips inquiry needs to answer is whether this distinction remains realistic in such sensitive (and scientifically uncertain) fields as BSE and its relationship to Creutzfeldt-Jakob disease, or whether new formulations can be imagined. Providing firm guidance on this alone will turn out to be a valuable contribution to modern politics. 